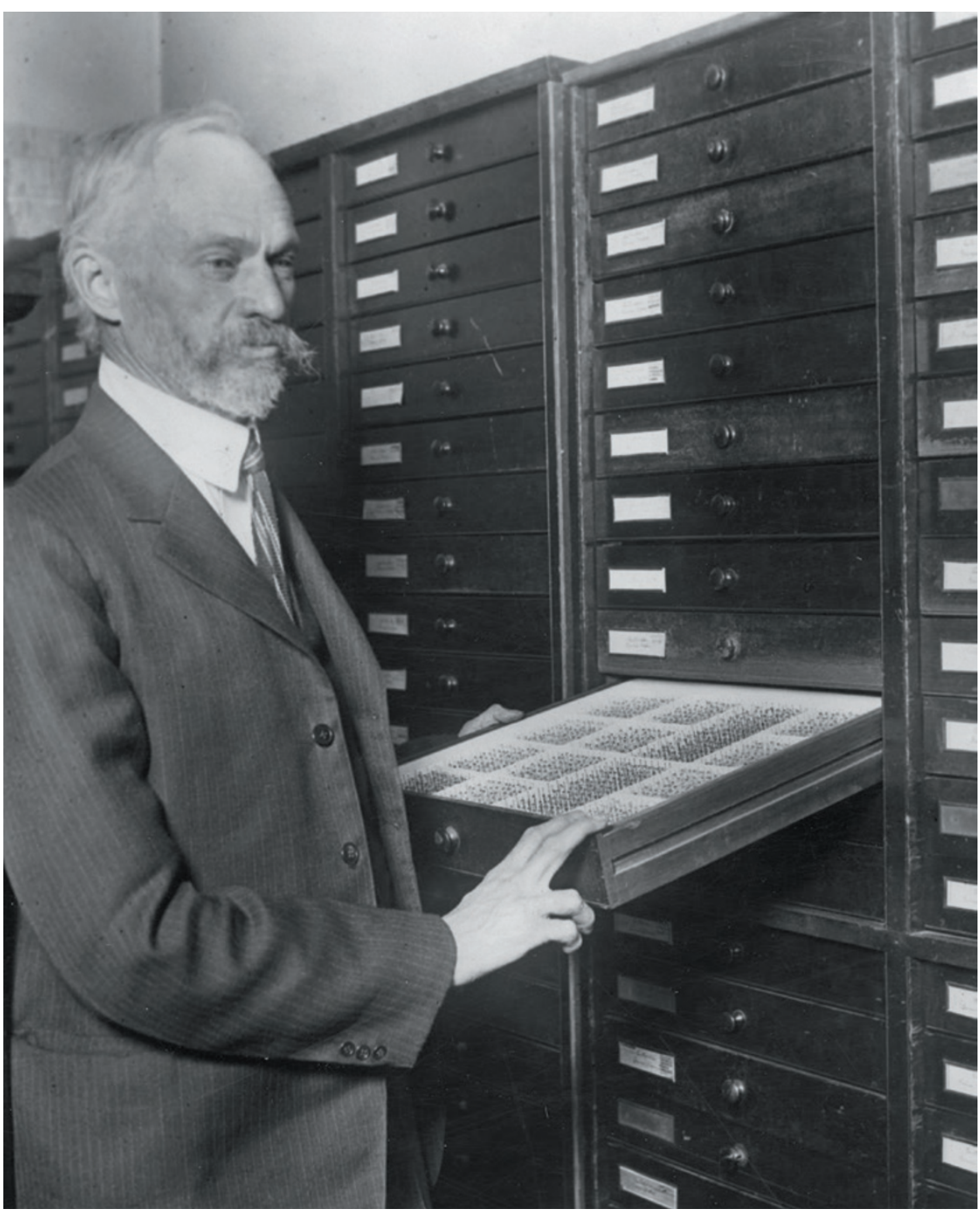

Harrison Dyar collected 500,000 different kinds of mosquitoes over his career.

ENTOMOLOGY

\title{
A life of insects and ire
}

\section{Professional feuds and private oddities abound in a biography of Harrison Dyar, finds William Foster.}

$\mathrm{H}$ arrison G. Dyar Jr (1866-1929) was an influential US biologist who became notorious in his own lifetime. His pioneering work changed our understanding of the biology and systematics of two globally important groups: the Lepidoptera (butterflies and moths) and mosquitoes. But his scientific legacy is overshadowed by his protracted, spectacularly belligerent feuds with fellow entomologists, and scandalous revelations about his private life. For some 14 years, he was married to two women, maintaining two families of five children in all. Towards the end of his life, he built an extensive system of brick-lined tunnels deep under the heart of Washington DC. When accidentally discovered in 1924, the tunnels caused such a sensation
Moths, Myths, and Mosquitoes: The Eccentric Life of Harrison Dyar MARC EPSTEIN Oxford University Press: 2016. nian Institution in Washington DC, where Dyar spent most of his professional career. To write Moths, Myths, and Mosquitoes, Epstein dug deep into the Smithsonian's holdings of publications, correspondence, diaries, unpublished short stories and novellas, newspaper articles and marriage certificates, providing rich context for Dyar's intellectual and scientific milieu. Epstein's descriptions of Dyar's collecting trips and battles with colleagues are particularly evocative.

Dyar's major scientific achievement was to establish the use of insects' immature stages in the construction of evolutionary trees, or phylogenies, based on Darwinian principles. His 1902 list of North American Lepidoptera has stood the test of time, as have most of his species classifications among the Lepidoptera, sawflies and mosquitoes. Among biologists he is perhaps best known for formulating Dyar's Law, which postulates that the width of the head capsule of each developmental stage, or instar, of a caterpillar is related by a constant ratio to the width of the head capsule of the next instar. When looking at a sample, this takes most of the guesswork out of deciding which instar you are dealing with, whether any are missing and how many a particular species might have. Epstein shows that Dyar fudged his data a little to fit his model, but the model itself remains useful. (It certainly worked for me when I did my first biology project, a demonstration of Dyar's Law, as a schoolboy in the mid-1960s.)

It is relatively difficult to establish objective measures of accuracy in systematics and phylogeny; as a result, researchers are often tempted to settle arguments by sheer force of personality. Dyar embraced this temptation with rash enthusiasm, even though his own research had enhanced the objectivity of the field. He seemed to relish long-running scientific battles. In 1905, he accused Henry Skinner, editor of Entomological News, of indulging in a "hysterical outburst", adding, "Better take a sedative." Skinner responded that Dyar drank "too much ice water", so his blood was "too frigid" to understand what went on in the News. In 1908, mosquito expert Evelyn Mitchell sued Dyar for libel. The case was dismissed, and Dyar got his revenge by writing an unpublished short story, "The Taming of a Suffragette', which features a thinly disguised Mitchell. As Moths, Myths, and Mosquitoes
DNATURE.COM Visit the Books \& Arts blog: nature.com/ booksandarts 
progresses, one begins to sense that the battles are what kept Dyar going. "Lest affairs become too monotonous, I feel obliged to start something occasionally," he wrote in 1925 , in a letter to Leland Howard, his superior at what is now the US National Museum of Natural History.

Much of the book, in particular the sections on Dyar's private life, feels like the raw materials of a biography rather than a finished product. Epstein fields a wonderful set of characters, but struggles to breathe life into them; many passages are cluttered with detail. Nor is it always easy to work out the sequence of events, but the many excellent illustrations and photographs help to shape and colour the narrative. There is a particularly moving photo of Dyar and his two-year-old son Otis on a beach, staring rather gloomily into the camera. Next to them is a huge sand sculpture of a spiny limacodid caterpillar: even at the seaside, there is no escape from Dad's work.

In the epilogue, Epstein offers definitive proof of when Dyar's bigamy began. Dyar married Zella Peabody in 1889, fathering two children with her before their divorce in 1920. Yet in 1906, Dyar had secretly married Wellesca Pollock under the name of Wilfred P. Allen. He had three children with Pollock; surreally, she later "Heconstructed tried, and failed, a labyrinth of to obtain a divorce tunnels lined from the imaginary with bricks and Allen. In 1917, Dyar furnished with was exposed for the electric lights." deception and dismissed from government service.

However appalling Dyar's behaviour to relatives and colleagues (he described Smithsonian librarian Mathilde Carpenter as a "boisterous, screaming plebian" in a letter to her supervisor), there is something oddly admirable about his final obsession. While digging a hollyhock bed for Peabody, he found himself 2 metres down, and was seized with the urge to keep going. He constructed a labyrinth of tunnels lined with bricks and furnished with electric lights, sculpted animal heads and mottos from Virgil. He claimed that they provided him with exercise. And no biologist could fail to admire Dyar's unquenchable respect for the insects that he studied. When the US government set out to exterminate mosquitoes in Yosemite National Park, California, Dyar protested, saying that a few bites are "good for hikers and lend zest to the fisherman's waiting".

William Foster is curator of insects at the University Museum of Zoology in Cambridge, UK; senior lecturer in the Department of Zoology at the University of Cambridge; and editor-in-chief of Biological Reviews. e-mail:waf1@cam.ac.uk

\section{Books in brief}

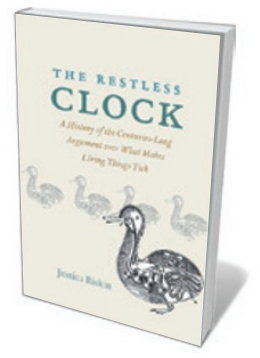

The Restless Clock: A History of the Centuries-Long Argument Over What Makes Living Things Tick

Jessica Riskin UNIVERSITY OF CHICAGO PRESS (2016)

At the heart of this scientific and cultural history is the concept of agency — the capacity to act — in nature. Jessica Riskin reveals how two distinct interpretations emerged from the mechanical Universe of the Enlightenment: Isaac Newton's passive version, reliant on a divine tinkerer; and Gottfried Leibniz's, which saw life as purposeful and "self-transforming". Riskin's investigation of this duality, by way of Renaissance automatons, the gestation of evolutionary theory and quantum mechanics, is engrossing and illuminating.

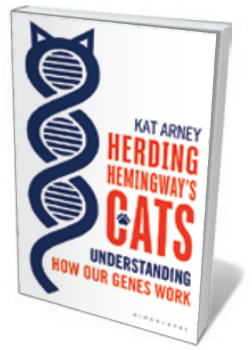

Herding Hemingway's Cats: Understanding How Our Genes Work Kat Arney BLOOMSBURY SIGMA (2016)

In this witty, clued-up report from the front lines of genetics, science communicator and broadcaster Kat Arney unravels the intricacies of the discipline with a romp through 'thumbed' cats, hipped fish and frank interviews with scientists such as evolutionary biologist Dan Graur. As she synthesizes key findings, she deploys a host of droll, yet apt, metaphors (including the human genome as a grim cabletelevision channel featuring tedious repeats), and pulls no punches in laying out the vast gaps in our understanding and the rancorous debates within the field.

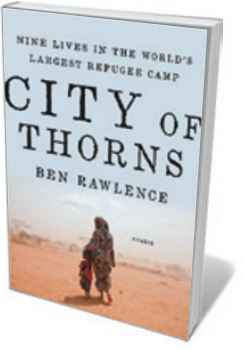

City of Thorns: Nine Lives in the World's Largest Refugee Camp Ben Rawlence PICADOR (2016)

Dadaab in the Kenyan desert is the world's largest refugee camp, a last-ditch home to some half a million people fleeing violence in the Horn of Africa. In this trenchant, densely layered sociopolitical study, investigative journalist Ben Rawlence reveals Dadaab's complexities through the lives of nine residents, impossibly courageous survivors of derailed cultures, imploded cities and sundered families. A reminder that although there are thousands of refugees at Europe's borders, millions more languish in camps - as Rawlence puts it, between "impossible dreams and a nightmarish reality".

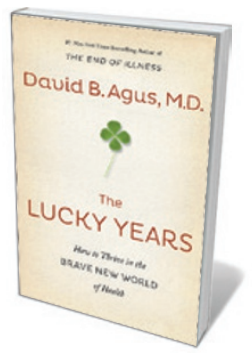

The Lucky Years: How to Thrive in the Brave New World of Health David B. Agus SIMON \& SCHUSTER (2016)

Oncologist and biomedical researcher David Agus's bestselling The End of IIIness (Simon \& Schuster, 2012; see Nature 480, $177 ; 2011$ ) argued persuasively for personalized health care. In this clear-cut follow-up, he details health interventions including monitoring technologies, analysable aggregate data sets and, more controversially, smartphone apps that detect signs of depression. What is strongest here is Agus's deft marshalling of research old and new, and his common-sense guidance on preventives such as sleep hygiene and the optimal level of exercise (450 minutes per week).

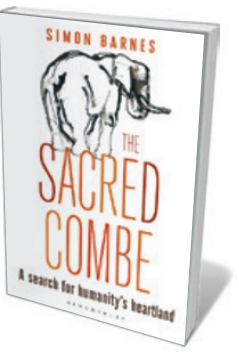

The Sacred Combe: A Search for Humanity's Heartland

Simon Barnes BLOOMSBURY NATURAL HISTORY (2016)

The moment a herd of elephants ripped into his thatched hut did it for natural-history writer Simon Barnes: he suddenly realized that Zambia's Luangwa Valley had claimed him for its own. This episodic journey into the wilds of Devonshire, Africa and memory - the edenic spaces where species fleetingly coexist - is studded with descriptive jewels. Here, for instance, are eland antelopes, "one-tonners drifting back like pale wisps of smoke", and an otter with "elegant bum briefly sky-pointing" as it dives in for the hunt. Barbara Kiser 